\title{
Microbial communities and inflammatory response in the endometrium differ between normal and metritic dairy cows at $5-10$ days post-partum
}

Ron Sicsic ${ }^{1}$, Tamir Goshen ${ }^{1,2}$, Rahul Dutta ${ }^{1}$, Noa Kedem-Vaanunu' ${ }^{1}$ Veronica Kaplan-Shabtai ${ }^{1}$, Zohar Pasternak ${ }^{3}$, Yuval Gottlieb ${ }^{1}$, Nahum Y. Shpigel ${ }^{1}$ and Tal Raz ${ }^{*}$ (D)

\begin{abstract}
Post-partum metritis is among the most prevalent disease in dairy cows affecting animal welfare and inflicting considerable economic loses. While post-partum contamination of the uterus is rife in dairy cows, only a fraction of these animals will develop metritis. Our main objective was to compare the bacterial communities and the inflammatory response in the endometrium of healthy and metritic dairy cows. Holstein-Friesian cows $(n=35)$ were sampled immediately following clinical classification as healthy $(n=21)$, suffering from metritis $(n=13)$ or septic metritis $(n=1)$, based on veterinary examination at $5-10$ days post-partum. Polymorphonuclear cells (PMN) percentage in endometrial cytology was significantly higher in cows with metritis. Full-thickness uterine biopsy analysis revealed that the luminal epithelium in inter-caruncle areas was preserved in healthy cows, but in metritis it was compromised, with marked PMN infiltration particularly in the apical endometrium. Gram staining revealed that bacterial load and spatial distribution was associated with disease severity. 16S-rDNA bacterial community analysis revealed unique endometrial bacterial community composition in metritic cows, as compared to more diverse communities among healthy cows. The most abundant phyla in healthy cows were Proteobacteria (31.8 $\pm 9.3 \%)$, Firmicutes $(27.9 \pm 8.4 \%)$ and Bacteroidetes (19.7 $\pm 7.2 \%$ ), while Bacteroidetes (60.3 $\pm 10.3 \%)$, Fusobacteria (13.4 $\pm 5.9 \%)$ and Firmicutes $(10.5 \pm 3.3 \%)$ were most abundant in the endometrial mucosa of metritic cows. Relative abundance of Bacteroidetes $(19.7 \pm 7.2 \%$ vs. $60.3 \pm 10.3 \%)$, Fusobacteria ( $7.5 \pm 5.2 \%$ vs. $13.4 \pm 5.9 \%)$ and Proteobacteria ( $31.8 \pm 9.3 \%$ vs. $7.3 \pm 5.6 \%)$ phyla differed significantly between healthy and metritic cows. In summary, endometrial PMN abundance, spatial distribution and bacterial communities differed between healthy and metritic dairy cows at early post-partum.
\end{abstract}

\section{Introduction}

Post-partum uterine inflammatory diseases are among the most prevalent diseases in bovine dairy herds worldwide, resulting in major economic losses, mainly through decreased reproductive performance and milk production of affected cows [1-3]. After parturition the uterine endometrium undergoes an involution process, which

\footnotetext{
*Correspondence: tal.raz@mail.huji.ac.il

1 Koret School of Veterinary Medicine, Robert H. Smith Faculty of Agriculture, Food and Environment, The Hebrew University of Jerusalem, Rehovot, Israel

Full list of author information is available at the end of the article
}

is characterized by massive tissue remodeling; myometrium contractions, shrinkage of the uterus, sloughing of the caruncles and endometrial regeneration [4]. The presence of epithelial tissue debris and fluid during this period makes the uterine environment favorable for bacterial growth [5]. According to an earlier report [6], nearly $100 \%$ of dairy cows are affected by bacterial contamination of the uterus at the first 2-3 weeks post-partum, which may often lead to uterine infection and disease. Although the immune system progressively clears most of the bacterial load, $25-40 \%$ of animals may have clinical metritis in the first 2 weeks after calving, 
and the disease may persist as subclinical endometritis in up to $20-30 \%$ of animals $[7,8]$.

The pathophysiology of uterine diseases in post-partum dairy cows is not completely clear. It is not well understood how in some animals the essential inflammatory process for normal uterine involution develops into metritis and endometritis. This could possibly be affected by a combination of certain microbes that enter the postpartum uterus or are present in the uterus shortly after or even during pregnancy $[9,10]$, as well as by the defense mechanism and the immune reaction of the cow $[6,11$, 12]. The severity of clinical manifestation may depend on the type of bacterial population. Culture-dependent microbiological analysis has revealed the presence of several microbes in the uterus of post-partum metritic cows, such as Escherichia coli, Trueperella pyogenes, Fusobacterium necrophorum, Prevotella melaninogenica, Bacteroides spp., Pseudomonas spp., Streptococcus spp., and Staphylococcus spp. [13]. However, in recent years, the advancement of culture independent studies of the bacterial communities of post-partum bovine uteri using various techniques, such as DGGE profiling [14, 15], T-RFLP [16], FTIR spectroscopy [17], clone library sequencing $[14,16,18]$, and next generation sequencing of 16S-rDNA amplicon libraries [15, 19-23], has led to different results than culture based studies, and has made it possible to identify some bacteria that are difficult to grow in routine classical cultures. Since the analysis in culture independent studies relies on DNA isolated from the sample, it is probable that not all identified bacteria in a sample are viable. Nevertheless, culture independent methods are a powerful tool, and knowing the differences in diversity of the uterine microbiota between healthy and metritic cows may provide additional insight into the bacterial communities related to uterine disorders and the pathophysiology of these reproductive diseases. This knowledge is critical for the development of efficient prevention and therapeutic intervention.

It is well documented that periparturient dairy cows undergo a transition period, in which they may have diminished immune competence due to the interplay of multiple factors like metabolic changes, oxidative stress, nutritional imbalances, and stress due to pain during prolonged parturition and lactation; and therefore, the effectivity of the immune response against microbial challenges may be altered [24-26]. Polymorphonuclear cells (PMN) are the first and most significant inflammatory cells to be recruited from the peripheral blood circulation into the endometrium and uterine lumen as part of the post-partum uterine immune response to microbes [7]. Therefore, a higher percentage of PMN is usually found in cows suffering from uterine inflammatory diseases in comparison to healthy cows. However, the normal phagocytic activity of the neutrophils may be compromised by endocrine and metabolic changes around the time of parturition [27]. This impairment of the ability of neutrophils to respond to infectious challenges in periparturient dairy cows may potentially contribute to the high incidence of metritis in early lactation $[28,29]$. However, there is a lack of information regarding the distribution and activity of the PMN in affected uterine tissue sections.

Numerous studies have reported endometrial cytological analysis from the fourth week post-partum onward. Endometrial cytological analysis of the first 2 weeks post-partum is usually not performed, in part because of technical difficulties (large, thin walled and abdominal uterus), but mainly because the clinical diagnosis of uterine disease at this time (metritis) relies on obvious clinical signs, such as enlarged uterus and mucopurulent fetid vaginal discharge [30, 31]. Histopathological studies of full thickness biopsies of the bovine uterus in the first 2 weeks post-partum are indeed available [32-34], but unfortunately those studies are limited by a lack of specimens suffering from metritis, no description of PMN spatial distribution, and the fact that most of the samples were obtained by necropsy.

The objective of this study was to compare healthy Holstein-Friesian dairy cows to cows diagnosed with metritis in the early lactation (5-10 days in milk; DIM), in regard to uterine cytology (endometrial swabs), histology (full thickness uterine biopsies), bacterial communities (16S-rDNA pyrosequencing analysis of swab and biopsy samples) and reproductive performance.

\section{Materials and methods}

\section{Animals and study design}

All animal procedures were performed by licensed veterinarians with consent of the animal owner and approved by the Agricultural Research Organization Animal Care Committee for the Hachaklait, Mutual Society for Veterinary Services (Approval No. IL-233/10). Post-partum Holstein-Friesian cows $(n=35)$ of different parities (1-6) were included in this cross-sectional study. Cows were housed in loose housing systems in large, completely covered open sheds and fed a total mixed ration according to the recommendations of the Nutrient Requirement of Dairy Cattle. Cows were milked three times daily in a computerized milking parlor, with an average annual milk yield of $11500 \mathrm{~kg}$ per cow, corrected to 305-days of lactation. Included cows had no history of retained fetal membranes, post-parturient hypocalcemia or mastitis in the current lactation, and did not receive antibiotic or anti-inflammatory treatments prior to sampling. Examination and sampling were performed at 5-10 DIM by the same veterinary practitioner. 
Cows were classified as healthy or suffering from metritis as described previously [6, 31]. Briefly, clinical metritis diagnosis was based on the presence of foul smelling, red-brown watery to viscous purulent vaginal discharge, trans-rectal palpation of a thin walled, large uterus containing large amounts of fluid or gas, and the absence of systemic clinical signs such as pyrexia, anorexia or reduction in milk production. Cows with the clinical signs described above and systemic clinical signs (such as fever, anorexia, or depression) were classified as suffering from septic metritis (one cow that was used for full thickness biopsy sampling, as described below). Cows that did not present any of these clinical findings (uterus size and thickness expected for 5-10 DIM, a watery red vaginal discharge without foul smell, and no systemic clinical signs) were classified as healthy. Full individual cow health and reproduction data during lactation were collected from the herd management software (NOA, Israeli Cattle Breeders Association, Caesarea, Israel).

\section{Endometrial cytology and DNA sampling}

Endometrial cytology sampling was performed at 5-10 DIM by the same veterinary practitioner from 30 cows. Prior to sampling, the vulva was washed with a clean brush and soap water, followed by wipes containing 2-propanol and chlorhexidine-gluconate. After placing a clean plastic sleeve on the arm used for sampling, the vulva was lubricated with a sterile lubricant and a sterile double guarded endometrial culture swab (Equi-Vet, Denmark, Cat. No. 290955) was placed through the vagina at the external os of the cervix. Upon retraction of the hand from the vagina, vaginal discharge was evaluated for appearance and volume of secretions and for foul odor, as part of the clinical examination. The same hand was then inserted rectally, and the uterus was palpated to evaluate size, content, thickness of the uterine wall and the degree of involution. The swab was then guided through the cervix into the base of the right uterine horn on the medial side. The tip of the swab was extracted from the protective sheaths, pressed to the endometrium and rotated 5-6 times. The tip was retracted into the protective sheaths, and the swab was taken out of the vagina. The process was repeated with another swab after re-cleaning the vulva and changing the sleeve. Two swabs were successfully obtained from all cows. The tips of the swabs were broken at the indentation on the inner sheath, sealed with the sterile supplied caps, and transferred within $1 \mathrm{~h}$ at $4{ }^{\circ} \mathrm{C}$ to the laboratory. The first swab was used for DNA extraction and 16S-rDNA bacterial community analysis and the second swab was used for cytological analysis.

The cytology swab was placed in a sterile $15 \mathrm{~mL}$ Polypropylene tube containing $1 \mathrm{~mL}$ of sterile phosphate buffered saline (PBS). The liquid immersed swab was mixed by vortex at 3000 RPM for $10 \mathrm{~s}$ to assist biological matter transfer to the solution. Aliquots of $800 \mu \mathrm{L}$ of the resultant suspension were loaded onto glass slides by a Cytospin ${ }^{\mathrm{TM}}$ centrifuge (Cytospin ${ }^{\mathrm{TM}} 3$, Thermo-Shandon, Waltham, MA USA). Slides were stained with Diff-Quick, and were evaluated by a single experienced observer, who was blinded to the origin of the slides and the status of the cow. Cytological evaluation was done at a magnification of $400 \times$ (Nikon Eclipse E400, Tokyo, Japan). For each Diff-Quick stained slide, 100 cells per field (excluding red blood cells) were counted in 10 different fields, and used to calculate PMN percentage in the sample.

\section{Full thickness uterine biopsy sampling}

Full thickness biopsies (from serosa to mucosa) were obtained from five cows by the same veterinary practitioner. Standing right flank laparotomy was performed to obtain biopsies from four of these cows at 7-9 DIM: two cows diagnosed with metritis and two were defined as healthy according to the criteria described above. A fifth biopsy was obtained by necropsy $(<10 \mathrm{~min}$ post-mortem) of a cow that died at 7 DIM as a result of per-acute septic metritis. Prior to laparotomy, cows were sedated using $0.05 \mathrm{mg} / \mathrm{kg}$ intravenous Xylazine. Aseptic preparation and paravertebral anesthesia were performed at the area of intended incision $\left(\mathrm{T}_{13}-\mathrm{L}_{3}\right)$. The skin, subcutis and abdominal muscles were incised and bluntly dissected to create a modified grid approach to the abdomen as previously described [35]. The right uterine horn was identified and exteriorized through the incision. A $10 \mathrm{~cm}$ long and $5 \mathrm{~cm}$ wide spindle shaped full biopsy (from serosa to mucosa), containing a caruncle at mid-length, was taken from the greater curvature using a fresh sterile scalpel. The uterine horn, muscles and subcutis were sutured with 0-USP chromic cat-gut suture material. The skin was sutured using 0-USP nylon. Post-operative care included intramuscular oxytocin (50 IU; twice daily for 3 days), Penicillin-Procaine (20 $000 \mathrm{IU} / \mathrm{kg}$ once daily for 5 days) and Gentamycin ( $3 \mathrm{mg} / \mathrm{kg}$ once daily for 5 days). Later, three of the four cows had uncomplicated pregnancies and deliveries following artificial insemination (AI). The fourth suffered from perimetritis following surgery, and subsequently was not inseminated. The biopsy from the fifth cow was taken during necropsy from the same uterine location as described above.

The spindle shaped biopsies were transferred to a sterile area and handled with new sterile latex gloves and equipment. Each spindle biopsy was divided to three segments; one containing the caruncle and two intercaruncular segments. Each segment of the biopsy was subdivided into two sub-segments. One sub-segment was placed in a sterile $50 \mathrm{~mL}$ polypropylene tube containing 
$30 \mathrm{~mL}$ of $4 \%$ para-formaldehyde solution, and transferred to the laboratory for paraffin embedding. The other subsegment was flash frozen in liquid nitrogen, and stored at $-80{ }^{\circ} \mathrm{C}$ until DNA extraction and 16S-rDNA bacterial community analysis.

\section{Total DNA extraction and sequencing}

The DNA swabs $(n=30)$ were mixed with sterile PBS as described above and the samples were kept in $-80{ }^{\circ} \mathrm{C}$ until DNA extraction. Biopsy samples (one caruncular and one intercaruncular sample per cow; $n=5$ cows, 10 biopsies) were thawed and separately homogenized according to the extraction kit instructions. To avoid bias toward extraction of DNA from Gram negative bacteria, $2 \mathrm{mg}$ of lysozyme (Thermo Fisher Scientific, Cat. No. 89833) were added to each sample and incubated at $37^{\circ} \mathrm{C}$ for $1 \mathrm{~h}$. Total DNA was extracted from swabs and biopsy samples using AccuPrep ${ }^{\circledR}$ Genomic DNA Extraction Kit (BIONEER, Republic of Korea, Cat. No. k-3032) following the manufacturer's protocol.

Total DNA was used for 16S-rDNA bacterial tag encoded FLX amplicon pyrosequencing using the Roche 454 sequencing system as described previously [36]. The primers used for amplification prior to sequencing were 27F (5' GAG TTT GAT CNT GGC TCA G 3') and 519R (5' GTN TTA CNG CGG CKG CTG $3^{\prime}$ ), resulting in amplicons containing the $\mathrm{V} 1-\mathrm{V} 3$ region of the 16S-rRNA bacterial genes.

\section{S-rDNA bacterial community analysis}

The 16S-rRNA gene sequence fasta files (the standard text based format for representing nucleotide sequence $[37,38])$ and quality data were extracted from the SFF files generated by the 454 Titanium sequencer (MR DNA, Shallowater, TX USA). Average read length before trimming and quality control was $405 \mathrm{bp}$. Sequences were grouped according to barcode (1 mismatch allowed) and primer ( 2 mismatches allowed). Trimming, denoising and quality control were performed using MOTHUR v1.24 [39] according to the standard MOTHUR 454 protocol [40]. Sequences were aligned to the SILVA reference alignment database [39], and filtered to achieve perfect overlap while avoiding base pair overhang. Sequences were pre-clustered using the algorithm described by Huse et al. [41]. Chimeric reads were removed by execution of the UCHIME method using the MOTHUR software [42]. All the non-bacteria reads (chloroplast, mitochondria and kingdom level unclassified reads) were deleted from further analyses.

After cleaning and quality control, 96988 sequences with an average read length of 242 bp were left. Sequences with $>97 \%$ similarity were clustered into operational taxonomic units (OTUs) after calculation of pairwise distances between all reads. Phylotyping was based on current RDP-II taxonomy [43]. A data matrix of the OTUs was constructed-a separate column for each OTU and a separate row for each sample. Following relativization of the number of OTUs in a sample to the total number of 454 reads obtained from the same sample, a data point in the matrix corresponds to the abundance of a particular OTU in that sample. No rarefaction was performed for read abundance data following McMurdie and Holmes [44].

\section{Histopathology analysis}

Uterine biopsies were fixed immediately after collection in $4 \%$ para-formaldehyde solution for $24 \mathrm{~h}$, and later were dehydrated and paraffin embedded using routine procedure. Sections of $4 \mu \mathrm{m}$ thickness were stained using hematoxylin-eosin (H\&E) and Gram stains. Histological evaluation of these sections was performed using a light microscope (Axio Imager M1, AxioCam HRc camera; Carl Zeiss, Germany).

\section{Myeloperoxidase (MPO) immunohistochemistry}

Paraffin-embedded tissue sections $(4 \mu \mathrm{m})$ were dewaxed with xylene and ethanol. Sections were rehydrated in PBS ( $\mathrm{pH}$ 7.4) for $10 \mathrm{~min}$. The slides were then subjected to heat induced antigen retrieval in a decloaking chamber (Biocare Medical, CA, USA) at $110{ }^{\circ} \mathrm{C}$ for $3 \mathrm{~min}$. This was followed by cooling the slides in PBS. Slides were blocked with $10 \%$ fetal bovine serum (Biological Industries, Israel, 04-001-1A), 10\% bovine serum albumin (Amresco, 0332-TAM-50G) and 1\% Triton $\times 20$ (J.T.Baker,187-25-004) in PBS for $60 \mathrm{~min}$. Sections were carefully dried and incubated overnight at $4{ }^{\circ} \mathrm{C}$ with polyclonal rabbit anti-human Myeloperoxidase ready to use antibody (Dako Autostainer, Ref IS511). After being washed three times in PBS, sections were incubated for $1 \mathrm{~h}$ with CY5-conjugated goat anti-rabbit IgG (Abcam, Cat. No. ab97077) 1:250 in PBS at room temperature. Slides were washed three times in PBS and counterstained for $20 \mathrm{~min}$ with $0.1 \mathrm{mM}$ Sytox orange reconstituted in DMSO (Thermo Fisher, Cat. No. S11368). Slides were washed in PBS, dried off, and covered with a coverslip using an antifade media (Fluoro-Gel with Tris buffer; Cat. No. 17985-10, Electron Microscopy Sciences). Slides were examined using the Axio Imager M1 fluorescence microscope using MR3 camera (Carl Zeiss, Germany) with 50 Cy 5 and 43 HE DsRed channels.

\section{Statistical analysis}

Statistical analyses were performed using Statistix 8 software (Analytical Software, Tallahassee, FL USA); plots were produced by Prism 5.01 (GraphPad Software; San-Diego, CA, USA). Rarefaction curves of individual 
samples were plotted using the vegan v2.4-2 package in $\mathrm{R}$ software [45]. Descriptive statistics were calculated for all swab sampled cows $(n=30)$, and for the two groupshealthy $(n=19)$ and metritis $(n=11)$ cows, according to the clinical status definition, as described above. Differences between groups in cow parity, DIM on day of sampling, percent of PMN in cytological analysis and abundance of bacterial phyla/genera were analyzed using Wilcoxon Rank Sum Test. Differences were considered significant at $P<0.05$. Unless otherwise noted, results are presented as mean \pm SEM.

For 16s rDNA sequencing, 35 cow samples were used, including swab samples (healthy $n=19$; metritis $n=11$ ) and biopsy samples $(n=5$; healthy $n=2$, metritis $n=2$; septic metritis $n=1$ ). As the number of reads from healthy biopsy cows was very low, 33 samples (healthy swab $n=19$; metritis swab $n=11$; metritis biopsy $n=3$ ) were used for phylum level stacked bar plots (Figure 3), genus level MRPP test and NMDS ordination (see below). All other bacterial community analyses were performed on the swab samples $(n=30)$ exclusively. PC-ORD v6.08 (MjM Software, Gleneden Beach, OR) was used for multivariate analysis of sequencing data with Sorensen distances. For each of the swab sample groups, richness was defined as the number of OTU rows with a value greater the zero. Shannon diversity index $(\mathrm{H})$ was calculated by the equation $\mathrm{H}=\Sigma p_{i} \ln \left(p_{i}\right)$, where $p_{i}$ is the proportion of an $i$ th OTU in the data matrix. Evenness (E) was calculated as $\mathrm{E}=\mathrm{H} / \mathrm{ln}$ (richness).

Differences among the swabs of healthy and metritis groups and the biopsy metritis group (reads from intercaruncular biopsy sample) were calculated by multiresponse permutation procedure (MRPP) [46]. The size of the difference between the groups is represented by the A-statistic, and significance is represented by the MRPP P-value. Ordinations of the bacterial community of each cow were calculated by non-metric multidimensional scaling (NMDS) at 500 iterations [47].

Relative abundance was calculated as a percentage, by dividing the number of copies of a specific OTU (for some of the genera) or a set of OTUs (for Phyla, some genera) by the total number of OTUs found in either a specific cow (abundance) or a group of cows (mean abundance). Prevalence was calculated by dividing the number of cows in a specific group found to have at least one copy of the OTU of interest by the total number of cows in the group. Relative prevalence was calculated by dividing the prevalence of a specific genus in the metritis group by the prevalence of the same genus in the healthy group.

Indicator values (IV), representing the contribution of each OTU to the difference between the swab sample groups (healthy and metritis), were calculated using the method described by Dufrene and Legendre [48], based on a combination of the abundance and frequency of occurrence of each OTU in each group. The larger the IV (range 0-100), the more abundant and/or more frequent is an OTU in a given group compared to the other group; e.g., an OTU with the maximum value of 100 associated with healthy cows means the OTU is abundant and appears in all healthy cows and in none of the metritic cows.

\section{Results}

\section{Clinical and endometrial cytology analyses}

Overall, parity of sampled cows ranged from 1 to 6 $(2.7 \pm 0.3)$, and DIM at the sampling day from 5 to 10 ( $6.5 \pm 0.3$ days), with no significant difference between groups (healthy:parity $2.8 \pm 0.4$, DIM $6.8 \pm 0.3$ days; metritis:parity $2.4 \pm 0.4$, DIM $6.1 \pm 0.4$ days). The PMN percentage in endometrial cytology was significantly higher in cows with metritis (healthy: $10.1 \pm 3.1 \%$; metritis: $40.1 \pm 13.4 \% ; P=0.024)$. Reproductive performance parameters were better in the healthy cows as compared to cows diagnosed with metritis (Additional files 1 and 2).

\section{Histopathological analysis of uterine biopsies}

The results described below are from 5 cows (healthy $=2$, metritis $=2$, septic metritis $=1$ ), and as such are descriptive in nature. Histopathological evaluation of the H\&E stained sections of the uterus of healthy cows revealed that most of the luminal side of the intercaruncular regions was covered by an intact single layer columnar epithelium (Figures 1A-C). Vacuoles were apparent in epithelial cells, displacing the nucleus in some cells (Figures 1B and C). PMN infiltration between epithelial cells were noted in healthy animals (Figures $1 \mathrm{~B}$ and $\mathrm{C}$ ). Noticeably, in both metritic and septic metritic animals the epithelium was missing from the entire endometrial luminal surface (Figures $1 \mathrm{~F}-\mathrm{H}, \mathrm{K}-\mathrm{M}$ ). In the intercaruncular region of healthy animals, adjacent to the luminal side, the lamina propria shows an almost continuous line of hemorrhage accompanied by a mild, diffuse PMN infiltration (Figures $1 \mathrm{~A}-\mathrm{C}$ ). In case of the metritic animals, hemorrhages were not organized in a line, but were rather smaller, multifocal, and extended deeper into the lamina propria (Figure 1F), accompanied by a diffuse PMN infiltration extending from the luminal side to the level of endometrial glands, with occasional foci of heavy infiltration (Figures $1 \mathrm{G}$ and $\mathrm{H}$ ). In the septic metritic animal, thrombosis and vessel congestion were common findings, the PMN infiltration was extensively pronounced and was directed towards the luminal side (Figures $1 \mathrm{~K}-\mathrm{M}$ ). The increase in PMN presence with 


\section{Healthy}
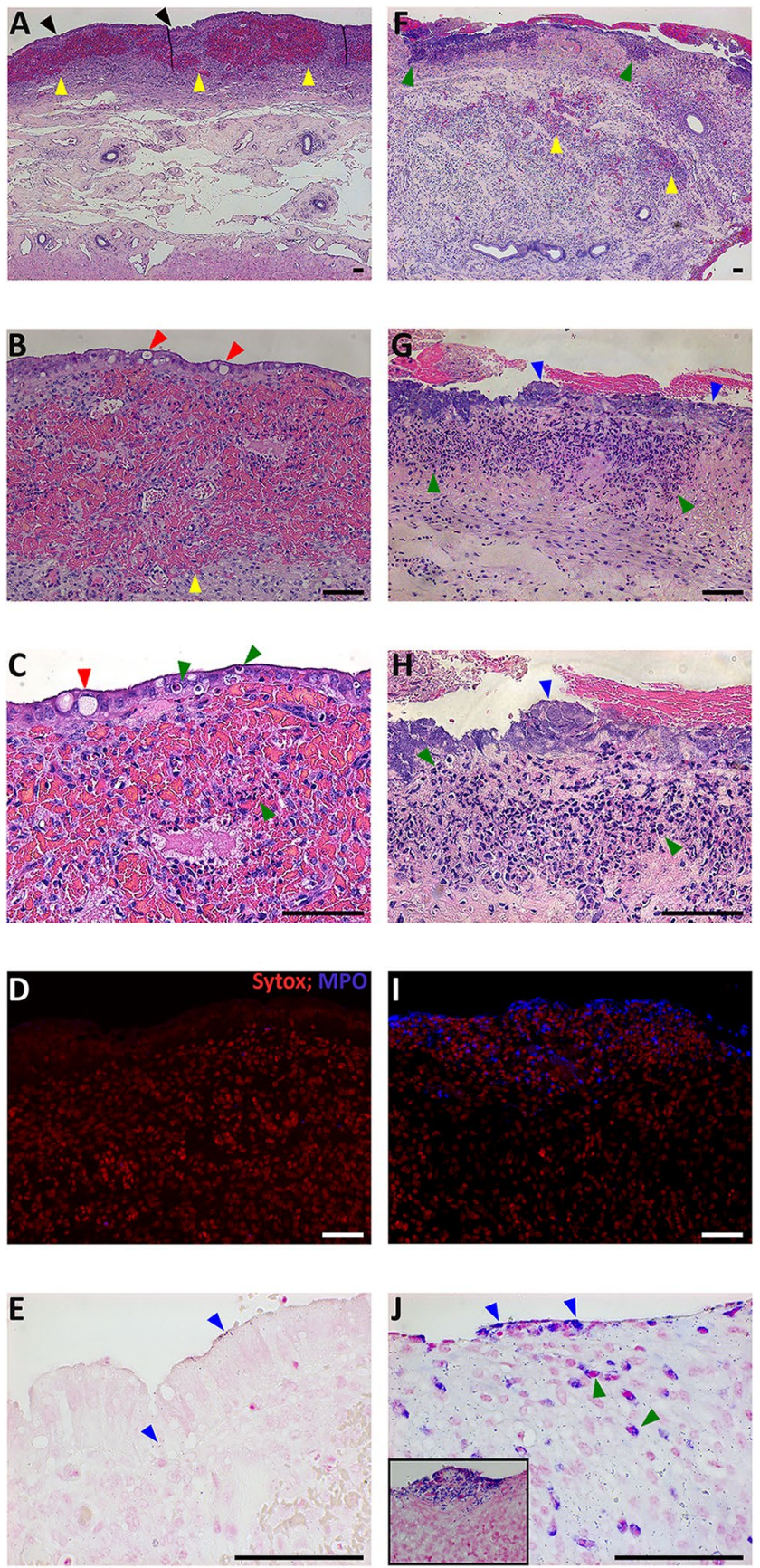

Metritis
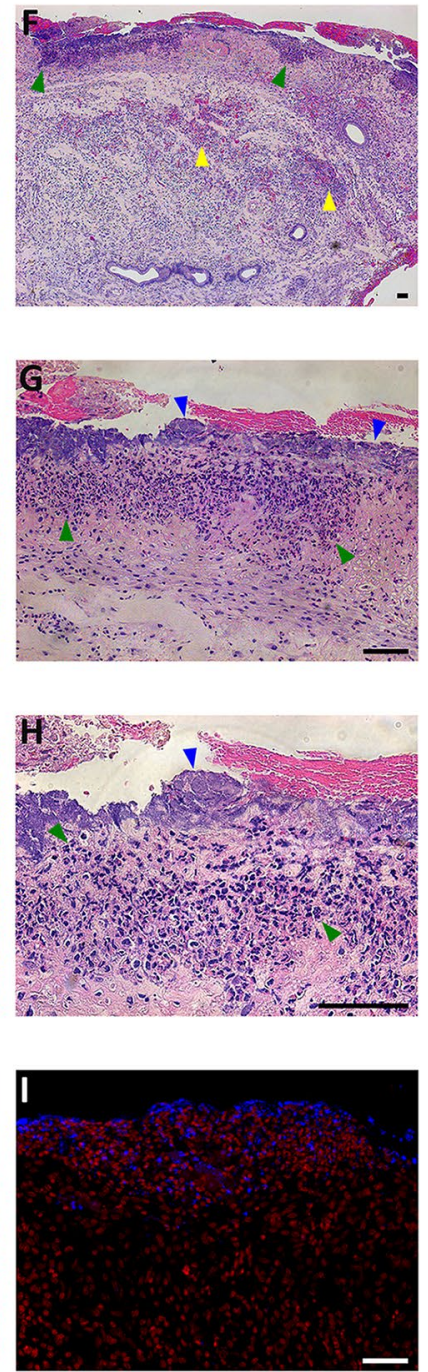
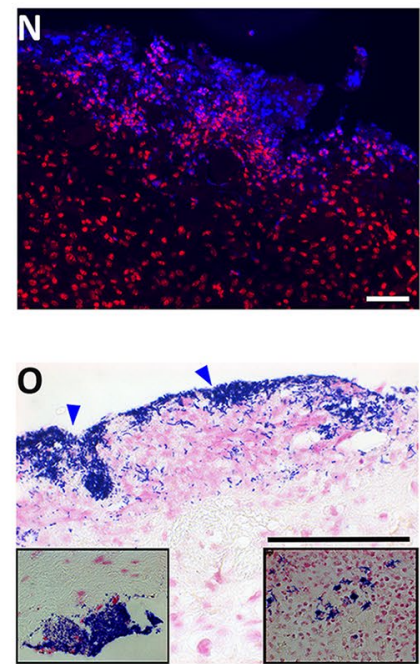

Figure 1 Histopathology of the endometrium in healthy, metritic and septic metritic cows at 5-10 days post-partum. Scale bars in all images are $50 \mu \mathrm{m}$. Colors mentioned in brackets refer to the arrowheads. Healthy cows: A-C H\&E stained sections, showing intact epithelium layer (black) with vacuoles (red) and PMN infiltration between cells and in the endometrium (green). A continuous hemorrhage line (yellow) can be seen adjacent to luminal epithelium. D Blue MPO immunohistochemistry with red Sytox orange counterstain shows minimal PMN presence. E Gram stain shows small amounts of bacteria (blue) on epithelium and minimal tissue invasion. Metritic cows: $\mathbf{F}-\mathbf{H}$ H\&E stain shows that the luminal epithelium is missing. Hemorrhages are deeper and multifocal (yellow). Foci of PMN infiltration are seen (green). Clumps of bacteria can also be seen (blue). I MPO immunohistochemistry shows PMN infiltration. J Gram stain shows clumps of bacteria on the luminal side (blue, inset), as well as phagocytosis of bacteria by PMN (green). Septic metritic cow: $\mathbf{K}-\mathbf{M}$ H\&E stained sections show absence of luminal epithelium. Blood vessel congestion (purple) and thrombosis (orange) are widespread, as is the massive PMN infiltration (green) and luminal bacteria presence (blue). N MPO immunohistochemistry confirms massive PMN infiltration. $\mathbf{O}$ Gram stain shows heavy bacterial load (blue) on luminal side, serosa (left inset) and invasion of endometrium (right inset). 


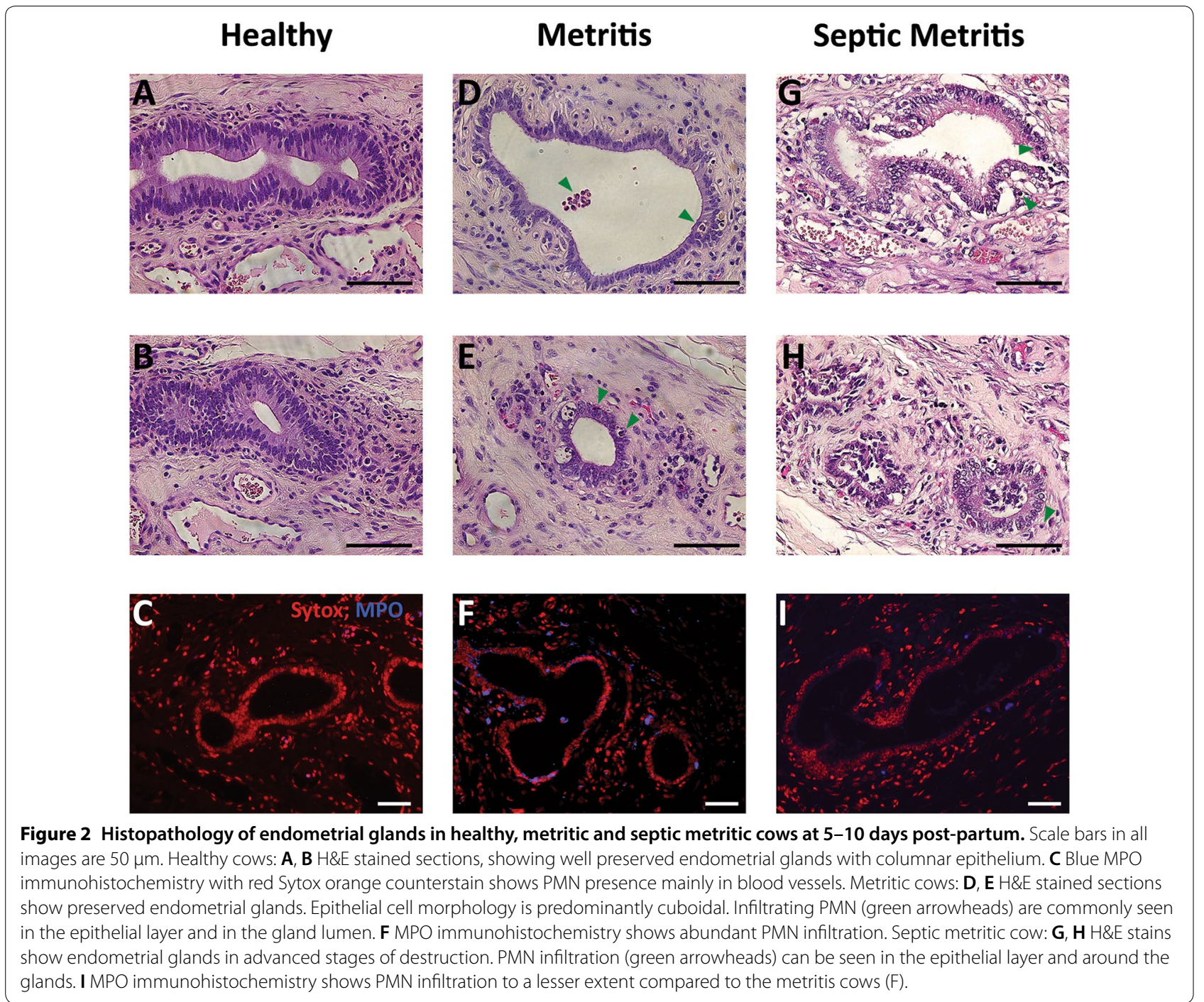

increasing severity of the clinical presentation was confirmed by MPO Immunohistochemistry (Figures 1D, I, $\mathrm{N})$.

The endometrial glands were conserved across the uterine sections of healthy and metritic cows (Figures 2A, B, D, E). Albeit, epithelial tubular cells had a columnar appearance in healthy cows and a more cuboidal shape in metritic animals. In the septic metritic sections, glands were in advanced stages of destruction (Figures $2 \mathrm{G}$ and $\mathrm{H})$. PMN infiltration between and into the gland lumen was more pronounced in sections from metritic and septic metritic animals (Figures 2D, E, G, H). MPO staining revealed minimal staining around the glands in healthy animals, and mild MPO staining around some of the glands in metritic cows (Figures $2 \mathrm{C}$ and $\mathrm{F}$ ). In septic metritic sections there was similar or lower MPO staining observed in the deeper glands as compared to sections of metritis (Figure 2I), although PMN infiltration in the $\mathrm{H} \& \mathrm{E}$ histologic sections was higher in septic metritis.

Bacteria spatial distribution and load, assessed by Gram and $H \& E$ stains, were associated with disease severity. In healthy cows, bacteria were scarce and concentrated in small groups on the endometrial luminal surface of the epithelium layer, with mild penetration into the tissue (Figure 1E). In metritic animals, bacteria were concentrated in large clumps on the luminal side (Figures 1G, H, $\mathrm{J})$; invasion of bacteria into the endometrium was more pronounced, accompanied by phagocytosis of bacteria by PMN (Figure 1J). In the septic metritic animal, bacteria clumps were spread across the entire luminal surface (Figures $1 \mathrm{~L}, \mathrm{M}, \mathrm{O}$ ), and also seen invading deeper into the endometrium as well as on the serosa surface (Figure $1 \mathrm{O}$, insets). Bacteria were not clearly demonstrated in glands in the Gram stain sections. 

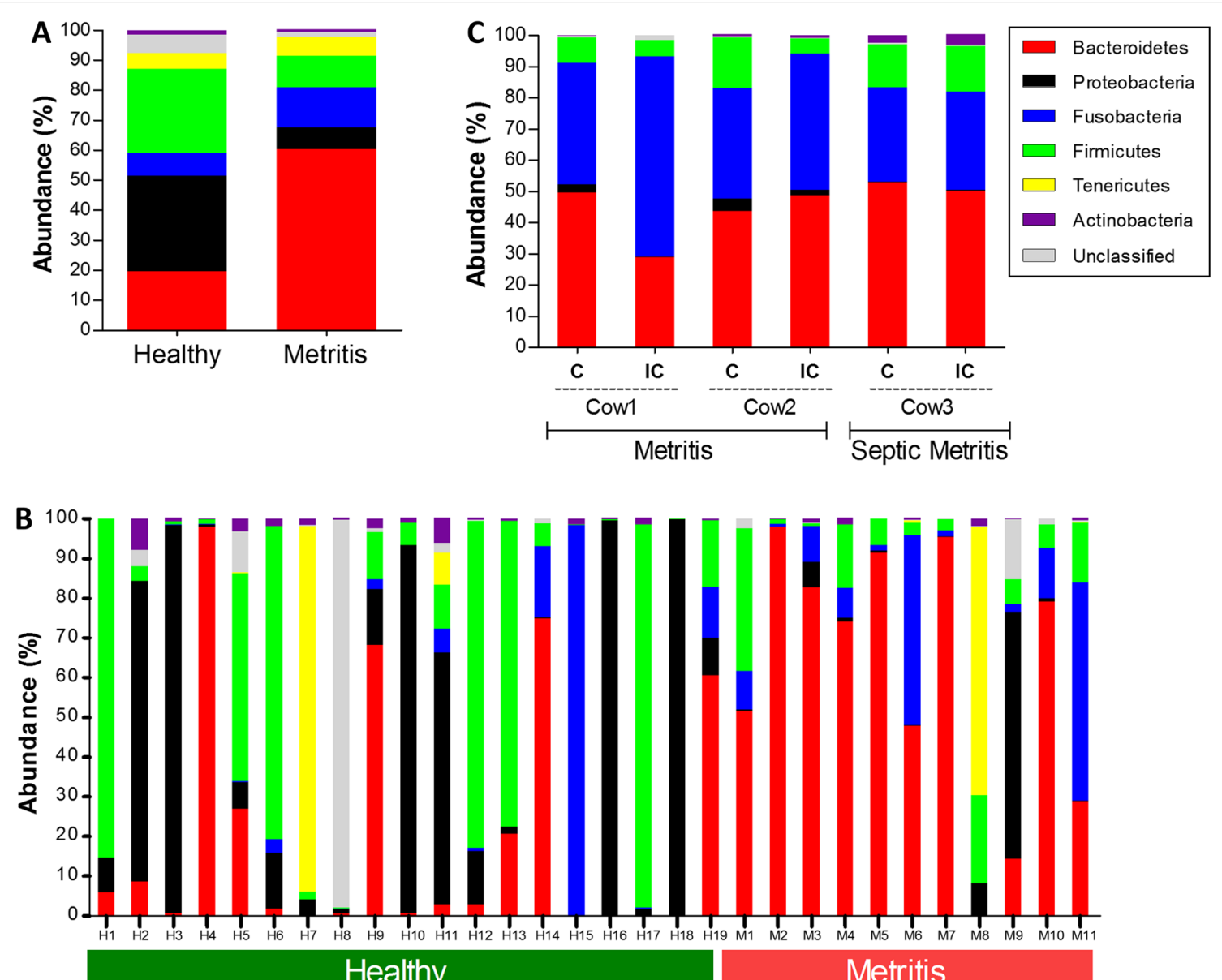

Figure 3 Stacked-bar plots of endometrial bacterial community composition by phylum, in healthy, metritic and septic metritic cows. A Average community composition of swab samples by phylum in healthy cows $(n=19)$ as compared to cows diagnosed with metritis $(n=11)$. Note the increased abundance of the Bacteroidetes phylum in metritic cows, mainly at the expanse of the Proteobacteria and Frimicutes phyla. B Community composition of individual endometrial swab samples by phylum in healthy cows $(n=19)$ and cows diagnosed with metritis $(n=11)$. Note the relatively uniform bacterial community composition of metritic cows compared to the more diverse composition of healthy cows. $\mathbf{C}$ Community composition of individual uterine biopsy samples from cows diagnosed with metritis ( $n=2$ cows) or septic metritis $(n=1$ cow); : caruncular samples; IC: inter-caruncular sample. Note the similarity between these abundance plots, the individual plots of metritic swab samples (B), and the mean metritic community composition (A).

Overall, in each cow, there were no notable differences in the H\&E sections observed between intercaruncular and caruncular sections, with the exception of the expected absence of endometrial glands in the caruncular sections, and luminal epithelium in the healthy cows, as described above.

\section{S-rDNA analysis of bacterial communities in swab and biopsy samples}

The 96988 high quality sequences obtained from 30 endometrial swab samples were assigned to 969 genus-level OTUs. Average number of reads per cow was $3233 \pm 393$ reads. Rarefaction curves (Additional file 3 ) reached a plateau for most cows, indicating that the sequences obtained closely represent the bacterial diversity of the sample taken from each cow [49]. Mean richness, evenness and Shannon diversity index of the healthy group were $54.6 \pm 21.1,0.4 \pm 0.06$ and $1.5 \pm 0.3$, respectively; in the metritis group, the parallel values were $45.5 \pm 5.7,0.4 \pm 0.03$ and $1.5 \pm 0.2$, respectively. None of the three alpha diversity parameters were significantly different between the groups.

For each of the swab cow groups (healthy vs. metritis), mean abundance of phyla was calculated, as summarized in Additional file 4 and presented in Figure 3A. In descending order, the most abundant phyla in healthy cows were Proteobacteria, Firmicutes and Bacteroidetes, and in metritic cows Bacteroidetes, Fusobacteria 
Table 1 High-quality read numbers of uterine biopsy samples collected from healthy, metritic and septic metritic cows

\begin{tabular}{|c|c|c|c|c|c|}
\hline \multirow[t]{2}{*}{ Tissue } & \multicolumn{2}{|c|}{ Healthy } & \multicolumn{2}{|c|}{ Metritis } & \multirow{2}{*}{$\begin{array}{l}\text { Septic metritis } \\
\text { Cow } 5\end{array}$} \\
\hline & Cow 1 & Cow 2 & Cow 3 & Cow 4 & \\
\hline & 1 & 20 & 5093 & 1494 & 2476 \\
\hline Inter-caruncle & 2 & 17 & 1959 & 4187 & 2203 \\
\hline
\end{tabular}

Number of reads obtained from 16S-rDNA pyrosequencing of biopsy samples, after trimming, denoising and quality control.

and Firmicutes. A statistically significant difference was found in the average percentage of the Bacteroidetes, Fusobacteria and Proteobacteria phyla between healthy and metritic cows. Bacterial community composition by phylum was also calculated separately for each individual swab sample (Figure 3B). The composition of the bacterial communities of healthy cows varied, and presented a wider set of options compared to the community compositions found in the metritic cows, which appear to be relatively uniform among most cows in that group. In addition, MRPP analysis showed a significant difference between the bacterial communities of healthy and metritic cows (swab metritis $A=0.0280$, $P=0.018)$.
High quality read numbers from biopsy samples are summarized in Table 1 . All healthy cow biopsy samples produced low read numbers, which prevented us from mapping the community composition in these cows. Stacked bar plots of community composition by phyla were constructed for each of the metritic cow biopsy samples, as shown in Figure 3C. MRPP analysis of biopsy samples compared to healthy swab samples showed a significant difference between the bacterial communities $(A=0.0313, P=0.032)$. There was also a tendency for a difference between the swabs and biopsies of metritic cows $(A=0.0496, P=0.061)$, which could be explained by differences in sample size, technical differences, or by the biopsy metritis group being a subset of the swab metritis group, with a much smaller intra-group distance, as is visible in the NMDS plot (Figure 4).

NMDS analysis (3D stress value $=0.138$ ) of healthy and both metritic groups (swab and biopsy samples) shows the same pattern as the individual stack bar plots (Figure $3 \mathrm{~B}$ ) - the bacterial communities of healthy cows are more dispersed along the axes, while the metritic group communities tend to cluster together. The metritis biopsy samples seem to represent a subgroup of the swab metritis group.

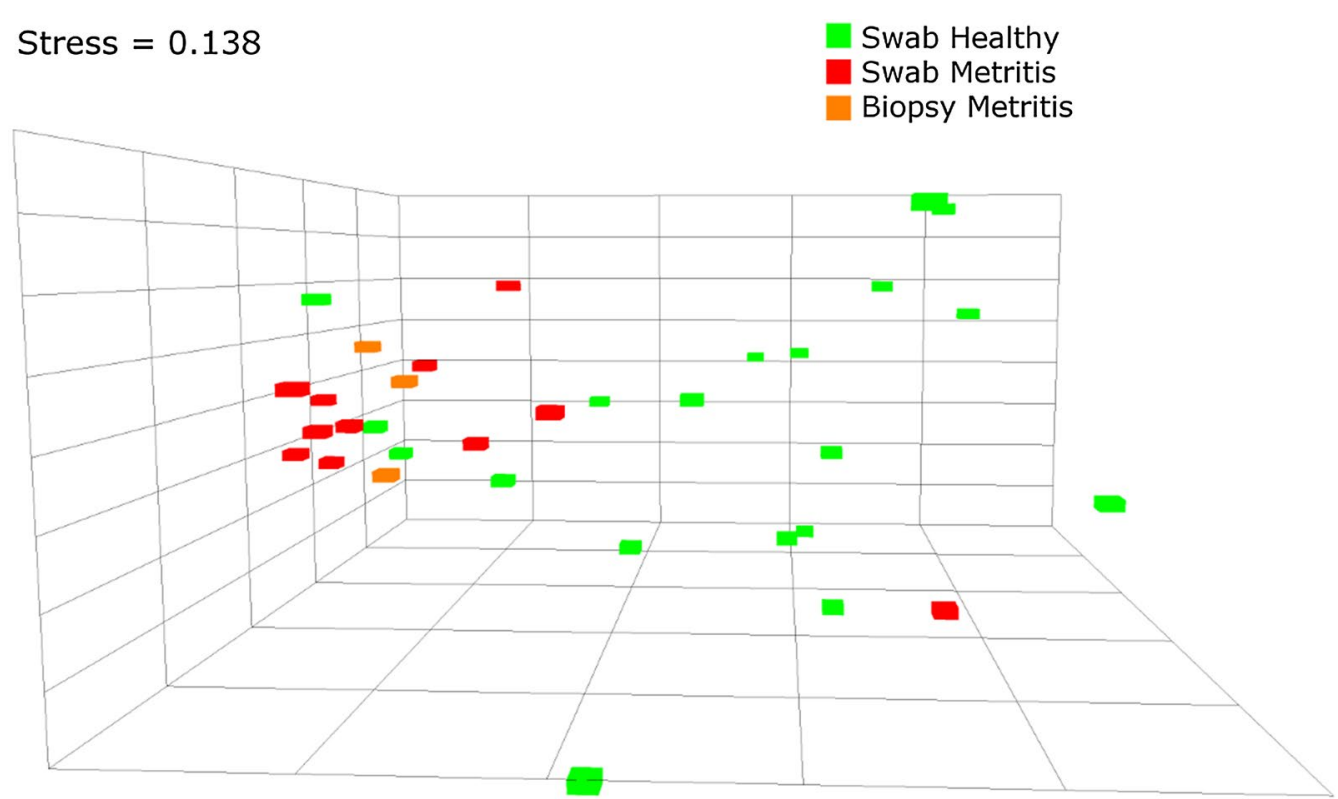

Figure 4 Non-metric Multidimensional Scaling (NMDS) ordination plot of endometrial bacterial community composition, in healthy and metritic cows. The axes and dimensions in NMDS are arbitrary. The "stress" value is a goodness of fit measure, representing how well the low dimensionality (3D) ordination represents the actual multi-dimensional (969D, as the number of OTUs) distance between each pair of samples. The lower the stress, the better the ordination. Stress values between 0.2 and 0.1 are considered acceptable. Notice the clustering of metritic cows (red and orange), in contrast to the more dispersed population of healthy cows (green). The biopsy metritic cows seem to be a subgroup of the swab metritis group, perhaps owing to differential penetration of bacteria from the lumen and epithelial surface (swab samples) to the interior structures of the uterine wall (biopsy samples). 
Table 2 Prevalence and mean abundance ( \pm SEM) of selected bacterial genera in healthy and metritic cows

\begin{tabular}{|c|c|c|c|c|c|}
\hline \multirow[t]{2}{*}{ Genus } & \multicolumn{2}{|l|}{ Prevalence } & \multicolumn{2}{|l|}{ Abundance } & \multirow[t]{2}{*}{$P$ value } \\
\hline & Healthy (\%) & Metritis (\%) & Healthy (\%) & Metritis (\%) & \\
\hline Bacteroides & 42.1 & 27.3 & $4.3 \pm 2.0$ & $10.7 \pm 4.4$ & 0.121 \\
\hline Escherichia/Shigella & 26.3 & 9.1 & $10.8 \pm 6.2$ & $0.5 \pm 0.5$ & 0.261 \\
\hline Fusobacterium & 68.4 & 90.9 & $2.8 \pm 1.2$ & $12.4 \pm 5.2$ & 0.013 \\
\hline Porphyromonas & 47.4 & 90.9 & $10.2 \pm 4.9$ & $29.8 \pm 8.0$ & 0.011 \\
\hline Trueperella & 47.4 & 72.7 & $0.2 \pm 0.1$ & $0.2 \pm 0.1$ & 0.288 \\
\hline
\end{tabular}

Samples were collected by endometrial swabs at 5-10 days post-partum and used for 16S-rDNA pyrosequencing analysis.

a The Escherichia/Shigella genera have a high similarity in the 16S-rRNA gene and thus both appear as the same OTUs according to the protocols used in this study.

Table 3 Indicator values of statistically significant genera in relation to clinical status (healthy vs. metritis) in postpartum cows

\begin{tabular}{lllll}
\hline Genus & Phylum & Clinical status & Indicator value & P value \\
\hline Fusobacterium & Fusobacteria & Metritis & 74 & 0.019 \\
Propionibacterium & Actinobacteria & Healthy & 65.4 & 0.011 \\
Bacteroides & Bacteroidetes & Metritis & 63.4 & 0.002 \\
Acinetobacter & Proteobacteria & Healthy & 60.8 & 0.012 \\
Cupriavidus & Proteobacteria & Healthy & 60.7 & 0.011 \\
Porphyromonas & Bacteroidetes & Metritis & 52.9 & 0.048 \\
\hline
\end{tabular}

Indicator value (IV) is an asymmetric index [48], used in this study to associate bacterial genera to cow clinical status, based on abundance and prevalence. The more abundant and prevalent the genus is in one group with a defined clinical status compared to the other, the higher the IV.

Prevalence and relative abundance of genera that are presumed to be metritis-associated pathogens according to previous studies were calculated for the swab samples (Table 2). Escherichia and Shigella genera have a high similarity in the V1-V3 region of the 16S-rRNA gene and are thus classified as a combined OTU (Escherichia/Shigella) according to the methods used in this study.

Bacterial genera associated with clinical status (healthy or metritis) with indicator values (IV) above 50 are shown in Table 3. Relative prevalence was calculated for the most prevalent genera in the metritis group (i.e., present in $>25 \%$ of metritic cows), by dividing the prevalence of a genus in the metritis group by the prevalence in the healthy group (Figure 5). This analysis showed a number of genera which present a combination of low abundance and high relative prevalence, such as Sneathia, Peptostreptococcus and Porphyrobacter. The genus Sneathia (phylum Fusobacteria) is outstanding in this aspect, with a prevalence of $0 \%$ in the healthy group compared to $54.5 \%$ in the metritis group (since the denominator is zero, an arbitrary value of 25 was assigned for the relative prevalence of Sneathia).

Some healthy cows (H4, H9, H14 and H19) present a bacterial community composition that is somewhat similar to the average metritic cow composition when classified by phyla. These four cows were designated as a subgroup, and analysis of the most abundant genera of each of the three dominant phyla (Bactroidetes, Firmicutes, Fusobacteria) were compared to the metritis group; as summarized in Additional file 5, there was no significant difference between the two subgroups average abundances in that analysis. Furthermore, these healthy cows were close to the metritis group in the NMDS ordination plot (labels not shown). However, the most notable difference was in the Fusobacteria phylum, with the genera Streptobacillus and Sneathia present only in the metritic cows but absent in the subgroup of these four healthy cows.

\section{Discussion}

The results of this study emphasize the differences between healthy Holstein-Friesian dairy cows to cows diagnosed with metritis in the very early lactation, in regards to their endometrial inflammation (as shown by cytology and histology analyses), bacterial communities composition, spatial distribution and load (as shown by the 16S-rDNA analysis and histopathology), as well as their reproductive performance. In Israel, most dairy cows are routinely examined by their veterinarian in order to clinically diagnose metritis according to the criteria described in this study. Endometrial cytological 


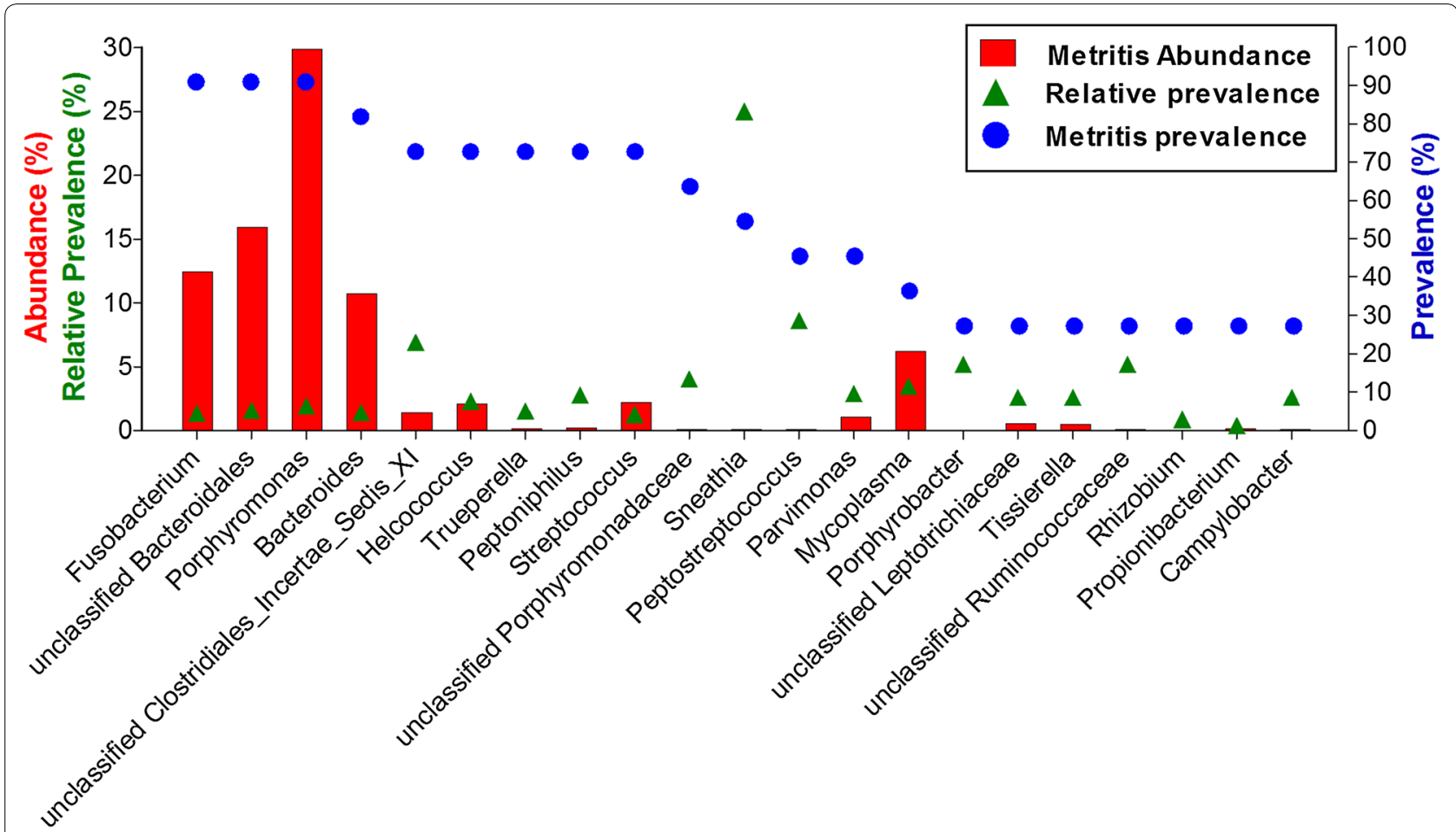

Figure 5 Prevalence, abundance and relative prevalence of frequent bacterial genera in metritic cows. Right $Y$ axis: the prevalence of genera that were present in $>25 \%$ of the metritic cows is shown by the blue dots. Left $Y$ axis: the red bars represent the mean abundance of the genera in metritic cows. The relative prevalence (prevalence of a genus in metritic cows divided by the prevalence of the same genus in healthy cows) is shown by the green triangles. Where the denominator (prevalence in healthy cows) was zero (i.e., Sneathia) an arbitrary value of 25 was assigned.

analysis during the first 10 days post-partum is not commonly performed. Interestingly, in this study, cows with metritis had a significantly higher cytologic PMN percentage at 5-10 DIM as compared to healthy cows; which is somewhat parallel to the results of other studies comparing cows with and without endometritis, commonly diagnosed cytologically much later in lactation $[50,51]$. The presence of a relatively high PMN percentage in cytological samples from healthy cows can be attributed to the early stages of the uterine involution process, which involves massive tissue remodeling and replacement, mediated by an inflammatory process, or possibly due to low sensitivity of the clinical classification. Another possible explanation for this finding is the presence of PMN as part of the innate immune reaction to bacterial contamination of the uterine lumen. The lower percentage of PMN in healthy cows might be due to an appropriate response to infection or greater tissue damage in metritic cows. However, it can also suggest a controlled and efficient inflammatory reaction in healthy cows, in contrast to excessive PMN mobilization to the uterus in metritic cows associated with the relevant clinical signs. This finding is concurrent with the difference in the severity and depth of infiltration and in PMN mobilization observed between healthy and metritic cows in the histopathologic analysis, suggesting that cytological analysis of the superficial layer of the endometrium and luminal fluid can closely indicate the severity of the inflammatory process in deeper layers of the uterus [29]. Better reproductive performance of the healthy cows compared to cows diagnosed with metritis at 5-10 DIM may emphasize the potential benefit of such an early examination and diagnosis, as has been previously demonstrated by Goshen and Shpigel [31].

The histopathologic analysis results of the healthy cows are similar to those reported by previous studies [32-34]. The almost continuous line of hemorrhage observed adjacent to the luminal epithelium in the healthy cows led us to speculate as to the role of these hemorrhages in the early stages of normal involution. A possible explanation is that in healthy cows this continuous hemorrhage line may perhaps act as a barrier against bacteria trying to invade into the deeper layers of the uterus, either by mechanical interference (clot formation) or by concentrating the blood borne leukocytes close to the luminal surface, which serves as the entry point for invading bacteria. The ability of bacteria to invade the endometrium to a larger extent in metritic cows is probably aided by 
the absence of endometrial epithelial layer of these cows [52]. It is unclear from the current study whether this is a host defect acting as a risk factor for the development of metritis, or the result of the inflammatory process of metritis initiated by the presence of luminal bacteria. We used MPO as a marker for PMN presence as they contain a rich supply of the green heme enzyme MPO $[53,54]$. In general, the PMN were concentrated mainly in the luminal layers of the uterus. We could not observe deeper migration of PMN into the inner layers of the uterus (muscularis, serosa) in metritic animals, but the presence of PMN in the endometrium seems to be associated with the clinical presentation. Still, the relatively small number of cows used for histopathological sections (healthy $=2$ cows, metritis $=2$ cows, septic metritis $=1$ cow) do not allow robust statistical quantitative or semi-quantitative analysis; therefore, these results are descriptive in nature, and limit us from drawing definitive conclusions or causal inferences.

The bacterial community compositions in healthy cows exhibited a more diverse array as shown in individual stacked bar plots and NMDS analysis, while the bacterial community among cows with metritis was more uniform (as shown in Figures 3B and 4). These findings further strengthen the concept presented in previous studies [15, 21] of a limited set of pathogenic bacterial communities acting as the etiologic agents of metritis rather than few pathogens, each acting as single, independent etiologic agent.

The genus Fusobacterium, showed high prevalence and mean abundance in the swabs of cows in the metritic group. However, genera which are presumed to be important pathogens in the development of metritis in studies using culture-dependent methods [7], such as Escherichia and Trueperella, showed low mean abundance in the metritis group in the current study (even when assuming the Escherichia/Shigella OTU as representing the Escherichia genus only). Porphyromonas has been linked to bovine necrotic vulvovaginitis in a culture based study [55], but is not often present in cultures from uteri of metritic cows. Nevertheless, Porphyromonas is emerging as one of the most abundant pathogens associated with metritis in studies using culture-independent methods $[18,56]$, and appeared at higher prevalence and significantly higher mean abundance in the metritis group in this study. These findings are in line with the recent study by Cunha et al. [57], in which Escherichia coli and T. pyogenes quantification did not differ between healthy and metritic cows, while F. necrophorum and Porphyromonas levii quantification did differ between the groups. The results suggest a possible bias in studies relying on culture-dependent methods towards species amenable to cultivation. However, bias also exists in studies of microbial communities based on sequence methodologies, mainly due to choice of DNA extraction method or materials, the initial PCR amplification [58], primer selection [59], as well as sequencing and taxonomic classification errors. We would like to suggest accepting data from culture-based and culture-independent studies as complementary parts of the same picture, while taking into consideration the potential bias arising from each of these methods.

Indicator values calculated in this study showed $\mathrm{Bac}$ teroides, Fusobacterium and Porphyromonas to be associated with metritis, supporting other type of analyses performed in this and other studies [56, 57, 60]. Acinetobacter, Cupriavidus and Propionibacterium were associated with healthy cows; these three genera belong to phyla more abundant in healthy cows-Proteobacteria and Actinobacteria.

The bacterial community analyses discussed above are based at least in part on abundance. In order to further explore the components of the microbial communities, the relative prevalence of high and low abundance genera were calculated. Interestingly, this analysis revealed high relative prevalence of certain low abundance genera in the metritis group, such as Peptostreptococcus and Sneathia. Peptostreptococcus has already been suggested to be involved in uterine infections $[18,21]$. Association of Sneathia with metritis in this study is in contrast to the findings reported in a recent study [21] which associated Sneathia with uterine health. Assuming a different environmental bacteria in the different studies (Florida vs. Israel), these conflicting results could be attributed to the contribution of the environmental bacteria in each study to the development of bacterial communities of the postpartum uterus. These high relative prevalence bacterial genera might have a larger role in metritis development than suggested by their relative abundance.

The similarity between the mean community composition of swab and biopsy samples in metritic cows could indicate that the main components of the bacterial community present on the surface epithelium and in the lumen (swab sample) are able to penetrate into the uterine tissue (biopsy sample); this is supported by the higher degree of bacterial invasion in metritic cows demonstrated in the Gram stained sections. However, differences are still present, in accordance with the recent report by Knudsen et al. [20]. Nevertheless, the biopsy samples from the metritic cows seem to form a subgroup of the swab metritic communities. This observation can be explained by the different tissue penetrating abilities certain bacteria possess, by which only some members of the metritic bacterial communities found in the lumen and barrier epithelium can actually invade the uterine wall and cause disease [20,61, 62]. 
One of the open questions regarding the pathophysiology of metritis is whether the ability of components of the bacterial communities to penetrate and infect the uterus is the primary cause of metritis, or alternatively, are certain cows unable to mount an effective immune response to a pathogenic bacterial community in the uterine lumen and therefore develop metritis, resulting in barrier dysfunction (such as epithelial necrosis, inadequate immune response), thus allowing the bacteria to invade the uterus. This question further resonates in our finding that some healthy cows present a community composition resembling that of metritic cows; however, there were still notable differences in the Fusobacteria phylum, with the genera Streptobacillus and Sneathia present only in the metritic cows but absent in the subgroup of these healthy cows.

The low number of high quality reads in the biopsy samples from healthy cows could be explained by technical errors, artefacts, a low ratio of bacterial DNA to bovine DNA (which composes most of the DNA extracted from the biopsy samples), sequencing error, or due to low sample size. However, if we assume that the low number of bacterial OTUs found in the healthy cow biopsy samples represents the true relative distribution of bacteria in the uterus tissue, a possible explanation is that while the uterine lumen of healthy cows is populated by bacterial communities (swab samples), the bacteria are not able to effectively invade into the uterus. Karstrup et al. [63] demonstrated that bacterial invasion from the lumen into the uterus is less frequent in healthy cows, and this can also be seen in the Gram stains in this study. Unfortunately, as taking full thickness biopsies is a complicated and invasive procedure, the amount of tissue samples in this study was limited and cannot allow us to reach binding conclusions as to the role of bacterial communities in swabs as compared to biopsies in healthy and metritic cows.

In summary, the current study indicates the differences between healthy Holstein-Friesian dairy cows and cows diagnosed with metritis at 5-10 days postpartum, in regards to the characteristics of the endometrial inflammation and bacterial communities' composition, spatial distribution and load, as well as the consequences on their reproductive performance. Bacterial community composition analysis revealed a unique bacterial community in most cows suffering from metritis, as compared to more diverse communities among cows which were defined as healthy. The inflammatory reaction and the luminal epithelium integrity differ between healthy cows and cows with metritis. Although yet to be fully understood, it is clear that the interplay between bacterial community composition and host response and defense mechanisms is important to disease development, as supported by the findings in the current study in regards to the epithelial layer integrity, PMN infiltration, localization and activity, in healthy cows compared to metritic cows. As post-partum uterine inflammatory diseases are among the most prevalent and economically impacting diseases in bovine dairy herds worldwide, understanding the pathophysiology of metritis is critical for developing effective therapies and prevention means in order to improve reproductive performance and animal welfare.

\section{Additional files}

\begin{abstract}
Additional file 1. Reproductive performance of healthy and metritic cows. Reproductive management was based on artificial insemination (Al) with thawed-frozen semen from proven sires. Al was performed by highly trained technicians employed by Sion LTD., Israel's leading company for dairy cow Artificial Insemination Service. Cows were bred on spontaneous estrus observed or detected by computerized pedometry system. Estrus was confirmed by trans-rectal palpation of the reproductive tract at the time of Al. For pregnancy diagnosis, trans-rectal palpation of the uterus was performed at 40-50 days post-insemination. Reproductive performance parameters included the following: number of Al to conception, open days (days from parturition to conception), waste days (days from first Al to Al leading to conception; i.e., equals 0 if cow is pregnant from first Al), and pregnancy rate at 180 DIM. Data were analyzed by Wilcoxon rank sum test, or a Pearson's Chi square test analysis (to compare pregnancy rate at $180 \mathrm{DIM})$. Values presented in the table are mean $\pm \mathrm{SEM}$ for each group, or percentages (\%).
\end{abstract}

Additional file 2. Kaplan-Meyer survival analysis of time interval from parturition to pregnancy in healthy and metritic cows. KaplanMeier Survival analysis (Log Rank, Mantel-Cox) test was used to analyze differences in interval from parturition to conception. Time to pregnancy was significantly shorter in healthy cows (green) as compared to cows with metritis (red), $P=0.004$.

Additional file 3. Rarefaction curves of 16S-rDNA pyrosequencing endometrial samples from healthy, metritic and septic metritic cows. Rarefaction curves of the number of OTUs are presented as a function of read number. $\mathrm{H}$ - healthy cows, endometrial swab samples; $\mathrm{M}$ - metritic cows, endometrial swab samples; BM - metritic cows, full-thickness uterine biopsy samples; BS - septic metritis cow, full-thickness uterine biopsy sample.

Additional file 4. Endometrial bacterial community composition by phylum in healthy and metritic cows. Samples were collected by endometrial swabs at 5-10 days post-partum and used for 16S-rDNA pyrosequencing analysis. Results are presented as mean abundance \pm SEM. $P$ value is specified where a statistically significant difference was found between the groups; NS: not significant.

Additional file 5. Most abundant genera of the phyla Bacteroidetes, Firmicutes and Fusobacteria in healthy and metritic cows with similar community composition. Samples were collected by endometrial swabs at 5-10 days post-partum and used for 16S-rDNA pyrosequencing analysis. For each phylum, the ten most abundant OTUs were included in descending order. Some genera appear twice or more as distinct OTUs. *The healthy group is composed of four cows with a similar bacterial community composition to the average metritic cow community composition sorted by phylum.

\section{Abbreviations}

Al: artificial insemination; DIM: days in milk; H\&E: hematoxylin-eosin; IV: indicator value; MPO: myeloperoxidase; MRPP: multi-response permutation procedure; NMDS: non-metric multidimensional scaling; OTU: operational 
taxonomic unit,; PBS: phosphate buffered saline; PMN: polymorphonuclear cells.

\section{Competing interests}

The authors declare that they have no competing interests.

\section{Authors' contributions}

Conceived and designed the experiments: NYS, YG, TG. Performed the experiments: TG, RS, RD, NKV, VKS, NYS, YG, TR. Analyzed the data: RS, ZP, YG, NYS, TR. Wrote the manuscript: RS, RD, YG, NYS, TR. All authors read and approved the final manuscript.

\section{Acknowledgements}

We thank Ms. Nathalie Weizmann for technical help.

\section{Availability of data and materials}

The datasets used and/or analyzed during the current study are available from the corresponding author on reasonable request.

\section{Ethics approval and consent to participate}

This study was approved by the Agricultural Research Organization Animal Care Committee for the Hachaklait, Mutual Society for Veterinary Services (Approval No. IL-233/10). Consent of the animal owner was given prior to enrollment.

\section{Funding}

This study was supported by The Israel Dairy Board Fund (Grant Nos. 6680093-10, 705-0064-14)

\section{Author details}

${ }^{1}$ Koret School of Veterinary Medicine, Robert H. Smith Faculty of Agriculture, Food and Environment, The Hebrew University of Jerusalem, Rehovot, Israel. ${ }^{2}$ Hachaklait, Mutual Society for Veterinary Services, Caesarea Industrial Park, Caesarea, Israel. ${ }^{3}$ Department of Plant Pathology and Microbiology, Robert H. Smith Faculty of Agriculture, Food and Environment, The Hebrew University of Jerusalem, Rehovot, Israel.

\section{Publisher's Note}

Springer Nature remains neutral with regard to jurisdictional claims in published maps and institutional affiliations.

Received: 7 May 2018 Accepted: 16 July 2018

Published online: 02 August 2018

\section{References}

1. Gilbert RO, Shin ST, Guard CL, Erb HN, Frajblat M (2005) Prevalence of endometritis and its effects on reproductive performance of dairy cows. Theriogenology 64:1879-1888

2. Esslemont RJ, Peeler EJ (1993) The scope for raising margins in dairy herds by improving fertility and health. Br Vet J 149:537-547

3. Gilbert RO (2016) Management of reproductive disease in dairy cows. Vet Clin North Am Food Anim Pract 32:387-410

4. LeBlanc SJ, Osawa T, Dubuc J (2011) Reproductive tract defense and disease in postpartum dairy cows. Theriogenology 76:1610-1618

5. Walker CG, Meier S, Hussein H, McDougall S, Burke CR, Roche JR, Mitchell MD (2015) Modulation of the immune system during postpartum uterine inflammation. Physiol Genomics 47:89-101

6. Sheldon IM, Cronin J, Goetze L, Donofrio G, Schuberth HJ (2009) Defining postpartum uterine disease and the mechanisms of infection and immunity in the female reproductive tract in cattle. Biol Reprod 81:1025-1032

7. Sheldon IM, Williams EJ, Miller AN, Nash DM, Herath S (2008) Uterine diseases in cattle after parturition. Vet J 176:115-121

8. Wathes DC, Cheng Z, Chowdhury W, Fenwick MA, Fitzpatrick R, Morris DG, Patton J, Murphy JJ (2009) Negative energy balance alters global gene expression and immune responses in the uterus of postpartum dairy cows. Physiol Genomics 39:1-13
9. Moore SG, Ericsson AC, Poock SE, Melendez P, Lucy MC (2017) Hot topic: $16 S$ rRNA gene sequencing reveals the microbiome of the virgin and pregnant bovine uterus. J Dairy Sci 100:4953-4960

10. Karstrup CC, Klitgaard K, Jensen TK, Agerholm JS, Pedersen HG (2017) Presence of bacteria in the endometrium and placentomes of pregnant cows. Theriogenology 99:41-47

11. Peter S, Michel G, Hahn A, Ibrahim M, Lubke-Becker A, Jung M, Einspanier R, Gabler C (2015) Puerperal influence of bovine uterine health status on the mRNA expression of pro-inflammatory factors. J Physiol Pharmacol 66:449-462

12. Sheldon IM, Cronin JG, Healey GD, Gabler C, Heuwieser W, Streyl D, Bromfield JJ, Miyamoto A, Fergani C, Dobson H (2014) Innate immunity and inflammation of the bovine female reproductive tract in health and disease. Reproduction 148:R41-51

13. Williams EJ, Fischer DP, Pfeiffer DU, England GC, Noakes DE, Dobson H, Sheldon IM (2005) Clinical evaluation of postpartum vaginal mucus reflects uterine bacterial infection and the immune response in cattle. Theriogenology 63:102-117

14. Santos TM, Gilbert RO, Bicalho RC (2011) Metagenomic analysis of the uterine bacterial microbiota in healthy and metritic postpartum dairy cows. J Dairy Sci 94:291-302

15. Santos TM, Bicalho RC (2012) Diversity and succession of bacterial communities in the uterine fluid of postpartum metritic, endometritic and healthy dairy cows. PLoS One 7:e53048

16. Elkjaer K, Ancker ML, Gustafsson H, Friggens NC, Waldmann A, Molbak L, Callesen H (2013) Uterine bacterial flora in postpartum Danish Holstein dairy cows determined using DNA-based fingerprinting: correlation to uterine condition and calving management. Anim Reprod Sci 138:39-48

17. Wagener K, Prunner I, Pothmann H, Drillich M, Ehling-Schulz M (2015) Diversity and health status specific fluctuations of intrauterine microbial communities in postpartum dairy cows. Vet Microbiol 175:286-293

18. Peng Y, Wang Y, Hang S, Zhu W (2013) Microbial diversity in uterus of healthy and metritic postpartum Holstein dairy cows. Folia Microbiol 58:593-600

19. Machado VS, Oikonomou G, Bicalho ML, Knauer WA, Gilbert R, Bicalho RC (2012) Investigation of postpartum dairy cows' uterine microbial diversity using metagenomic pyrosequencing of the $16 \mathrm{~S}$ rRNA gene. Vet Microbiol 159:460-469

20. Knudsen LR, Karstrup CC, Pedersen HG, Angen O, Agerholm JS, Rasmussen EL, Jensen TK, Klitgaard K (2016) An investigation of the microbiota in uterine flush samples and endometrial biopsies from dairy cows during the first 7 weeks postpartum. Theriogenology 86:642-650

21. Jeon SJ, Vieira-Neto A, Gobikrushanth M, Daetz R, Mingoti RD, Parize AC, de Freitas SL, da Costa AN, Bicalho RC, Lima S, Jeong KC, Galvao KN (2015) Uterine microbiota progression from calving until establishment of metritis in dairy cows. J Appl Environ Microbiol 81:6324-6332

22. Jeon SJ, Cunha F, Ma XJ, Martinez N, Vieira-Neto A, Daetz R, Bicalho RC, Lima S, Santos JEP, Jeong KC, Galvao KN (2016) Uterine microbiota and immune parameters associated with fever in dairy cows with metritis. PLoS One 11:e0165740

23. Clemmons BA, Reese ST, Dantas FG, Franco GA, Smith TPL, Adeyosoye Ol, Pohler KG, Myer PR (2017) Vaginal and uterine bacterial communities in postpartum lactating cows. Front Microbiol 8:1047

24. Esposito G, Irons PC, Webb EC, Chapwanya A (2014) Interactions between negative energy balance, metabolic diseases, uterine health and immune response in transition dairy cows. Anim Reprod Sci 144:60-71

25. Dubuc J, Duffield TF, Leslie KE, Walton JS, LeBlanc SJ (2010) Risk factors for postpartum uterine diseases in dairy cows. J Dairy Sci 93:5764-5771

26. Trevisi E, Amadori M, Archetti I, Lacetera N, Bertoni G (2011) Inflammatory response and acute phase proteins in the transition period of high-yielding dairy cows. In: Veas F (ed) Acute phase proteins as early non-specific biomarkers of human and veterinary diseases. InTech, London, p 355

27. Burvenich C, Bannerman DD, Lippolis JD, Peelman L, Nonnecke BJ, Kehrli ME Jr, Paape MJ (2007) Cumulative physiological events influence the inflammatory response of the bovine udder to Escherichia coli infections during the transition period. J Dairy Sci 90(Suppl 1):E39-54

28. Lacetera N, Scalia D, Franci O, Bernabucci U, Ronchi B, Nardone A (2004) Short communication: effects of nonesterified fatty acids on lymphocyte function in dairy heifers. J Dairy Sci 87:1012-1014

29. Goff JP (2006) Major advances in our understanding of nutritional influences on bovine health. J Dairy Sci 89:1292-1301 
30. Sheldon IM, Dobson H (2004) Postpartum uterine health in cattle. Anim Reprod Sci 82-83:295-306

31. Goshen T, Shpigel NY (2006) Evaluation of intrauterine antibiotic treatment of clinical metritis and retained fetal membranes in dairy cows. Theriogenology 66:2210-2218

32. Gier HT, Marion GB (1968) Uterus of the cow after parturition: involutional changes. Am J Vet Res 29:83-96

33. Wagner WC, Hansel W (1969) Reproductive physiology of the post partum cow. I. Clinical and histological findings. J Reprod Fertil 18:493-500

34. Archbald LF, Schultz RH, Fahning ML, Kurtz HJ, Zemjanis R (1972) A sequential histological study of the post-partum bovine uterus. J Reprod Fertil 29:133-136

35. Turner AS, Mcllwraith CW, Hull BL (1989) Techniques in large animal surgery, $2^{\text {nd }}$ edn. Lea \& Febiger, Philadelphia

36. Dowd SE, Callaway TR, Wolcott RD, Sun Y, McKeehan T, Hagevoort RG, Edrington TS (2008) Evaluation of the bacterial diversity in the feces of cattle using $16 \mathrm{~S}$ rDNA bacterial tag-encoded FLX amplicon pyrosequencing (bTEFAP). BMC Microbiol 8:125

37. Pearson WR, Lipman DJ (1988) Improved tools for biological sequence comparison. Proc Natl Acad Sci U S A 85:2444-2448

38. Leonard SA, Littlejohn TG, Baxevanis AD (2007) Common file formats. Curr Protoc Bioinform 16(1):A.1B.1-A.1B.9. https://doi.org/10.1002/04712 50953.bia01bs16

39. Schloss PD, Westcott SL, Ryabin T, Hall JR, Hartmann M, Hollister EB, Lesniewski RA, Oakley BB, Parks DH, Robinson CJ, Sahl JW, Stres B, Thallinger GG, Van Horn DJ, Weber CF (2009) Introducing mothur: open-source, platform-independent, community-supported software for describing and comparing microbial communities. J Appl Environ Microbiol 75:7537-7541

40. 454 SOP-mothur. https://www.mothur.org/wiki/454_SOP. Accessed 18 July 2018

41. Huse SM, Welch DM, Morrison HG, Sogin ML (2010) Ironing out the wrinkles in the rare biosphere through improved OTU clustering. Environ Microbiol 12:1889-1898

42. Edgar RC, Haas BJ, Clemente JC, Quince C, Knight R (2011) UCHIME improves sensitivity and speed of chimera detection. Bioinformatics 27:2194-2200

43. Cole JR, Wang Q, Cardenas E, Fish J, Chai B, Farris RJ, Kulam-SyedMohideen AS, McGarrell DM, Marsh T, Garrity GM, Tiedje JM (2009) The Ribosomal Database Project: improved alignments and new tools for rRNA analysis. Nucleic Acids Res 37(Database issue):D141-145

44. McMurdie PJ, Holmes S (2014) Waste not, want not: why rarefying microbiome data is inadmissible. PLoS Comput Biol 10:e1003531

45. Oksanen J, Blanchet FG, Friendly M, Kindt R, Legendre P, McGlinn D, Minchin PR, O'Hara RB, Simpson GL, Solymos P, Stevens MH, Szoecs E, Wagner H (2018) Vegan: Community Ecology Package. R package version 2.4-6

46. Krishnaiah PR, Sen PK (1984) Nonparametric methods. Handbook of statistics, North-Holland; Sole distributors for the U.S.A. and Canada, vol 4. Elsevier Science Pub Co, Amsterdam

47. Mather PM (1976) Computational methods of multivariate analysis in physical geography. Wiley, London

48. Dufrene M, Legendre P (1997) Species assemblages and indicator species: the need for a flexible asymmetrical approach. Ecol Monogr 67:345-366
49. Magurran AE, McGill BJ (2011) Biological diversity: frontiers in measurement and assessment. Oxford University Press, Oxford

50. Dolatkhah B, Mahdavi AH, Rahmani HR, Edriss MA, Khorvash M (2013) Cytologic and histologic characteristics of endometritis in postpartum dairy cows. Ann Biol Res 4:70-76

51. Barlund CS, Carruthers TD, Waldner CL, Palmer CW (2008) A comparison of diagnostic techniques for postpartum endometritis in dairy cattle. Theriogenology 69:714-723

52. Galvao KN, Santos NR, Galvao JS, Gilbert RO (2011) Association between endometritis and endometrial cytokine expression in postpartum Holstein cows. Theriogenology 76:290-299

53. Parker H, Albrett AM, Kettle AJ, Winterbourn CC (2012) Myeloperoxidase associated with neutrophil extracellular traps is active and mediates bacterial killing in the presence of hydrogen peroxide. J Leukoc Biol 91:369-376

54. Klebanoff SJ, Kettle AJ, Rosen H, Winterbourn CC, Nauseef WM (2013) Myeloperoxidase: a front-line defender against phagocytosed microorganisms. J Leukoc Biol 93:185-198

55. Blum S, Mazuz M, Brenner J, Friedgut O, Stram Y, Koren O, Goshen T, Elad D (2007) Sample-based assessment of the microbial etiology of bovine necrotic vulvovaginitis. Theriogenology 68:290-293

56. Bicalho MLS, Machado VS, Higgins CH, Lima FS, Bicalho RC (2017) Genetic and functional analysis of the bovine uterine microbiota. Part I: metritis versus healthy cows. J Dairy Sci 100:3850-3862

57. Cunha F, Jeon SJ, Daetz R, Vieira-Neto A, Laporta J, Jeong KC, Barbet AF, Risco CA, Galvao KN (2018) Quantifying known and emerging uterine pathogens, and evaluating their association with metritis and fever in dairy cows. Theriogenology 114:25-33

58. Brooks JP, Edwards DJ, Harwich MD Jr, Rivera MC, Fettweis JM, Serrano MG, Reris RA, Sheth NU, Huang B, Girerd P, Vaginal Microbiome C, Strauss JF $3^{\text {rd }}$, Jefferson KK, Buck GA (2015) The truth about metagenomics: quantifying and counteracting bias in 16S rRNA studies. BMC Microbiol 15:66

59. Green SJ, Venkatramanan R, Naqib A (2015) Deconstructing the polymerase chain reaction: understanding and correcting bias associated with primer degeneracies and primer-template mismatches. PLoS One 10:e0128122

60. Azawi Ol (2008) Postpartum uterine infection in cattle. Anim Reprod Sci 105:187-208

61. Ibrahim M, Peter S, Wagener K, Drillich M, Ehling-Schulz M, Einspanier R, Gabler C (2017) Bovine endometrial epithelial cells scale their pro-inflammatory response in vitro to pathogenic Trueperella pyogenes isolated from the bovine uterus in a strain-specific manner. Front Cell Infect Microbiol 7:264

62. Karstrup CC, Pedersen HG, Jensen TK, Agerholm JS (2017) Bacterial invasion of the uterus and oviducts in bovine pyometra. Theriogenology 93:93-98

63. Karstrup CC, Agerholm JS, Jensen TK, Swaro LRV, Klitgaard K, Rasmussen EL, Krogh KM, Pedersen HG (2017) Presence and localization of bacteria in the bovine endometrium postpartum using fluorescence in situ hybridization. Theriogenology 92:167-175

Ready to submit your research? Choose BMC and benefit from

- fast, convenient online submission

- thorough peer review by experienced researchers in your field

- rapid publication on acceptance

- support for research data, including large and complex data types

- gold Open Access which fosters wider collaboration and increased citations

- maximum visibility for your research: over 100M website views per year

At BMC, research is always in progress.

Learn more biomedcentral.com/submissions 